EDUR • Educação em Revista. 2021; 37:e26101

DOI: http://dx.doi.org/10.1590/0102-469826101

(2) (1) https://creativecommons.org/licenses/by/4.0/

ARTIGO

\title{
A CONTRIBUIÇÃO DOS PROGRAMAS BRAFITEC E ENGENHEIRO 3I PARA O APERFEIÇOAMENTO DA INTERNACIONALIZAÇÃO DA UNIVERSIDADE
}

\author{
MARIZETE RIGHI CECHIN ${ }^{1}$ \\ ORCID: https://orcid.org/0000-0001-7651-8082 \\ LUIZ ALBERTO PILATTI ${ }^{2}$ \\ ORCID: https://orcid.org/0000-0003-2679-9191 \\ DÉCIO ESTEVÃO DO NASCIMENTO ${ }^{3}$ \\ ORCID: https://orcid.org/0000-0001-5902-6545 \\ BRUNO RAMOND 4 \\ ORCID: https://orcid.org/0000-0001-7772-8989
}

\begin{abstract}
RESUMO: O objetivo da presente pesquisa é comparar os Programas Engenheiro 3i com o Brasil France Ingénieur Technologie (Brafitec), quanto às instituições participantes, aos cursos envolvidos, ao financiamento ofertado, às exigências do idioma, ao trabalho em equipe, à presença de empresa parceira, ao conteúdo e à certificação, com o foco em identificar aspectos que podem aperfeiçoar a internacionalização da universidade. Trata-se de um estudo documental de natureza qualitativa. O Programa Engenheiro 3i, apesar de limitações financeiras importantes quando comparado com o Programa Brafitec, destaca-se por proporcionar um percurso formativo complementar, almejando um engenheiro que trabalha em equipe, enfrenta problemas reais e apresenta o domínio comunicativo em três idiomas. Conclui-se que programas de mobilidade produzem lições importantes para a internacionalização da universidade pública brasileira e para melhorar a qualidade do seu ensino e da sua pesquisa. Os três $i$ do Programa, proposto por duas instituições tecnológicas que querem se internacionalizar, aparecem como uma referência importante para pensar o devir da profissão engenheiro num mundo sem fronteiras.
\end{abstract}

Palavras-chave: Brafitec, Engenheiro 3i, internacionalização, Universidade

\footnotetext{
${ }^{1}$ Professora titular - Universidade Tecnológica Federal do Paraná (UTFPR), Campus Guarapuava. Guarapuava, PR, Brasil. $<$ mrcechin@utfpr.edu.br>

2 Professor titular - Universidade Tecnológica Federal do Paraná (UTFPR), Campus Ponta Grossa. Ponta Grossa, PR, Brasil. <lapilatti@utfpr.edu.br>

3 Professor titular - Universidade Tecnológica Federal do Paraná (UTFPR), Campus Curitiba. Curitiba, PR, Brasil. <decio@utfpr.edu.br>

${ }^{4}$ Professor-pesquisador/Enseignant-chercheur - Universidade de Tecnologia de Compiègne/ Université de Technologie de Compiègne (UTC). Compiègne, França. <bruno.ramond@utc.fr> 


\title{
THE CONTRIBUTION OF THE BRAFITEC AND ENGINEER 3I PROGRAM TO THE IMPROVEMENT OF THE UNIVERSITY'S INTERNATIONALIZATION
}

\begin{abstract}
The objective of this research is to compare the Engineer 3i Program with the Brazil France Ingénieur Technologie (Brafitec), regarding the participating institutions, the courses involved, the funding offered, the language requirements, the teamwork, the presence of a partner company, the content and the certification, with the focus on identifying aspects that can improve the internationalization of the university. This is a documentary study of a qualitative nature. The Engineer $3 \mathrm{i}$ Program, despite important financial limitations when compared to the Brafitec Program, stands out for providing a complementary formative path, aiming at an engineer who works in teams, faces real problems and presents communicative domain in three languages. We conclude that mobility programs produce important lessons for the internationalization of the Brazilian public university and for improving the quality of its teaching and research. The three i's of the Program, proposed by two technological institutions that want to internationalize, appear as an important reference to think about the becoming of the engineering profession in a world without borders.
\end{abstract}

Keywords: Brafitec, Engineer 3i, internationalization, University

\section{LA CONTRIBUCIÓN DE LOS PROGRAMAS BRAFITEC E INGENIERO 3I PARA PERFECCIONAR LA INTERNACIONALIZACIÓN DE LA UNIVERSIDAD}

RESUMEN: El objetivo de esta investigación es comparar los Programas de Ingeniero 3i con Brasil France Ingénieur Technologie (Brafitec), con relación a las instituciones participantes, los cursos involucrados, la financiación ofrecida, las exigencias de idioma, el trabajo en equipo, la presencia de una empresa asociada, el contenido y certificación con enfoque en identificar aspectos que puedan perfeccionar la internacionalización de la universidad. Se trata de un estudio documental de carácter cualitativo. El Programa Ingeniero 3i, a pesar de importantes limitaciones económicas en comparación al Programa Brafitec, se destaca por brindar un itinerario formativo complementario dirigido a un ingeniero que trabaja en equipo, afronta problemas reales y presenta dominio comunicativo en tres idiomas. Se concluye que los programas de movilidad producen lecciones importantes para la internacionalización de la universidad pública brasileña, para mejorar la calidad de su docencia e investigación. Las tres i del Programa propuestas por dos instituciones tecnológicas que quieren internacionalizarse aparecen como una referencia importante para pensar el futuro de la profesión de la ingeniería en un mundo sin fronteras.

Palabras clave: BRAFITEC, Ingeniero 3i, internacionalización, Universidad. 


\section{INTRODUÇÃO}

A internacionalização das Instituições de Ensino Superior (IES) assume, no início do século XXI, um caráter necessário e urgente, segundo o discurso global neoliberal que é imposto à sociedade. Essa fase do imperialismo é denominada de versão benevolente, com liderança na Comunidade Europeia (CE) e no setor educativo. O imperialismo que o setor educativo vive no momento foi precedido por duas outras fases. Na primeira fase, localizada entre 1870 e a Primeira Guerra Mundial, a África ficou repartida entre os estados europeus e parte da Ásia foi ocupada pelo Japão e Estados Unidos da América. A segunda fase do imperialismo tem o foco na reconstrução da Europa com sustentação do capitalismo fordista e na mercantilização das relações sociais. Na fase atual, a intenção é implantar uma política internacional de educação, um padrão europeu, que visa atingir o mundo. O imperialismo benevolente mostra-se constituído no Processo de Bolonha. A ideia é promover um modo de vida, de pensar, de agir e de consumir nos moldes da lógica do mercado europeu. Para socializar essa ideia hegemônica, a educação é o espaço e a universidade e os intelectuais os atores da nova ordem (LEITE; GENRO, 2012).

As consequências da homogeneidade dos currículos, das avaliações e acreditações e da veiculação de valores mercantis à educação estão na desconsideração do local, no ignorar a diversidade cultural, no rejeitar a história e a formação do sujeito político, no recusar "[...] o cotidiano vivido pelos diferentes sujeitos inseridos nas instituições universitárias, nas organizações e nos movimentos sociais" (LEITE; GENRO, 2012, p. 771).

Embora o cenário possa parecer coercivo e sem alternativas, há outras motivações para a internacionalização das universidades como a ampliação da capacidade de investigação, de conhecimento e de entendimento intercultural, sem que se percam os vínculos regionais e locais, a diversidade cultural e histórica e a formação política do sujeito (DIAS; NUNES, 2017).

Quanto à leitura neoliberal da internacionalização das IES, algumas iniciativas apresentam alternativas contra-hegemônicas. Uma delas está em Santos (2008), quando defende alternativas de investigação, formação, extensão e organização como contribuição específica da universidade como bem público, a serviço da definição e solução coletiva de problemas sociais, nacionais e globais. Santos (2008) aponta como solução contra-hegemônica a implantação de um projeto nacional que valorize e considere a educação como bem público e que prepare os estudantes para a construção de uma sociedade sustentável e justa.

A sugestão de Santos (2008) foi a alternativa que a Associação Nacional dos Dirigentes das Instituições Federais de Ensino Superior (Andifes) escolheu para as IES públicas no Brasil. A cartilha denominada de Universidades federais: patrimônio da sociedade brasileira (ANDIFES, 2017) mostra que o Sistema Público de Universidades Federais é único no país em termos de formação de recursos humanos, desenvolvimento tecnológico, prestação de serviço à comunidade e promoção da cidadania. A iniciativa da Andifes valoriza a universidade como parte da história do Brasil e vai no sentido oposto à hegemônica. Ao lançar a cartilha, valoriza cada instituição, a diversidade cultural nacional e a formação política dos diferentes sujeitos inseridos nas universidades. A iniciativa inibe a homogeneidade e a padronização da universidade, foco da internacionalização hegemônica.

A prática da internacionalização da universidade acontece quando: há mobilidade internacional dos professores, alunos e dirigentes; existe uma rede de trabalhos conjuntos e publicações em parceria; são firmados acordos de dupla diplomação; há programas interinstitucionais estabelecidos e quando ocorrem programas de formação de recursos humanos (DIAS; NUNES, 2017).

Como cenário que baliza a prática da internacionalização de uma IES, o desafio está em "[...] promover o desenvolvimento de habilidades de comunicação intercultural, aprender sobre as culturas dos outros países, melhorar as habilidades para trabalhar em ambientes multiculturais e transformar-se em pessoas internacionais, preparadas para os desafios do futuro" (STALLIVIERI, 2017, p.18).

A prática da internacionalização nas universidades vem sendo debatida nas IESs, e publicações demonstram o quanto as universidades estão imersas nessa prática. Stallivieri (2017) escreve sobre conceitos, benefícios, tendências, riscos e desafios da internacionalização da universidade. Oregioni (2017) trabalha o conceito de internacionalização nas IES na América Latina. Wunenburger (2017) escreve sobre a importância do setor de Serviço Geral de Relação Internacional (SGRC) das universidades europeias para a mobilidade de estudantes da graduação, do mestrado e do doutorado. Dias e Nunes (2017) avaliam a internacionalização das universidades federais da região sul do Brasil no aspecto dos 
acordos internacionais para a mobilidade de alunos, de docentes e de técnico-administrativos. Charle (2013) trata das transformações das universidades europeias, sobretudo a partir de 1980, período em que a internacionalização ganha destaque, além de tratar do aumento do financiamento privado nas universidades.

A Universidade Tecnológica Federal do Paraná (UTFPR) é uma das 69 IES públicas federais do Brasil. Dos mais de 300 campi vinculados às universidades, 13 estão vinculados à ela. Nasceu em 2005 da transformação do Centro Federal de Educação Tecnológica do Paraná (CEFET-PR) em universidade tecnológica. Ainda como CEFET-PR, a prática da internacionalização já acontecia com a Universidade de Tecnologia de Compiègne (UTC), localizada na França, instituição que influenciou fortemente o modelo de universidade tecnológica adotado pela UTFPR e que, na época, era a maior parceira internacional do CEFET-PR.

$\mathrm{Na}$ atualidade, a UTC é uma das principais parceiras da UTFPR. A UTC foi fundada em 1972, sendo a $66^{a}$ universidade criada na França. É um estabelecimento público de caráter científico, cultural e profissional, que atua exclusivamente com cursos de engenharia (UTC, 2013). O foco do presente estudo são dois programas de mobilidade e de formação humana vigentes entre a UTFPR e a UTC: o Programa Engenheiro 3i, um dos mais recentes programas da prática de internacionalização entre as instituições, e o Brasil France Ingénieur Technologie (Brafitec), um programa entre os governos brasileiro e francês, consolidado e em vigor há mais de 15 anos.

No que se refere aos programas que serão cotejados neste estudo, a literatura sobre o Programa Engenheiro $3 i$ ainda é incipiente. O texto de Cziulik et al. (2016), escrito ainda na fase do seu planejamento, evidencia o desafio de criar uma proposta inovadora para a formação do engenheiro do futuro. No estudo, fica evidente o quanto o tempo e o planejamento fazem parte das bases para se firmar um programa internacional entre instituições. Em Cechin, Pilatti e Ramond (2018) tem-se o perfil do professor para atuar com o Programa 3i. Quanto ao Brafitec, Grochocki (2016a, 2016b) o tomou como objeto de sua dissertação.

Considerando a prática da internacionalização das IES, no viés do desenvolvimento humano, para melhor compreender e viver em ambiente diferente e de cultura diversificada, cabe o questionamento: como os programas de mobilidade Engenheiro 3i e Brasil France Ingénieur Technologie (Brafitec) se inserem no projeto de internacionalização das instituições participantes, particularmente as brasileiras, considerando os cursos envolvidos, o financiamento ofertado, as exigências do idioma, o trabalho em equipe, a presença de empresa parceira, o conteúdo e a certificação?

O objetivo da pesquisa é comparar os Programas Engenheiro 3i com o Brasil France Ingénieur Technologie (Brafitec) quanto às instituições participantes, aos cursos envolvidos, ao financiamento ofertado, às exigências do idioma, ao trabalho em equipe, à presença de empresa parceira, ao conteúdo e à certificação com o foco em identificar aspectos que podem aperfeiçoar a internacionalização da universidade.

O presente estudo caracteriza-se como documental, de natureza qualitativa. O corpus documental é constituído pelos editais da Chamada de seleção para o Programa Engenheiro 3i (UTFPR, 2017), da Chamada de seleção para o Programa CAPES/Brafitec (UTFPR, 2018), Edital n. ${ }^{\circ} 13 / 2017$ da CAPES (2017), dos diapositivos dos encontros realizados até 2017 (RAMOND, 2017) e os diários de bordo dos autores durante as reuniões interinstitucionais do Programa Engenheiro 3i. Os dados levantados foram submetidos à técnica da análise de conteúdo e foram observados os parâmetros propostos por Bardin (2016).

\section{PROGRAMA UTFPR-UTC ENGENHEIRO 3I}

O Programa Engenheiro 3i começou a ser formatado em uma reunião que aconteceu em 2015, no Brasil, na qual gestores da UTFPR e a UTC discutiam o futuro do ensino das engenharias. Na ocasião, o então reitor da UTC, Alan Storck, comentou que o engenheiro do futuro deveria ser capaz de pensar o social, o econômico e o tecnológico com agilidade e responsabilidade, e que a formação desse perfil seria o próximo desafio da cooperação entre a UTC e a UTFPR, pois colaborações de intercâmbio de estudantes e de funcionários, de cursos de dupla diplomação e de estágios em empresas parceiras já 
estavam consolidados. Como resposta ao desafio, foi perspectivado o avanço do programa Engenheiro 3i. O nome $3 \mathrm{i}$ faz referência ao perfil do engenheiro que o Programa procura construir, com características da Indústria, da Inovação e da Interculturalidade (RAMOND, 2017).

O perfil Indústria volta-se à formação do engenheiro preparado para atuar em um ambiente com pessoas e processos implicados na produção e na oferta de algo (bem, produto, serviço). Esse ambiente exige cada vez mais profissionais capazes de compreender, formular e solucionar problemas, na concepção de projetos voltados à solução dos desafios sociotécnicos das empresas globalizadas, com habilidade empreendedora e de forma conjunta com equipes interculturais e interdisciplinares. $O$ perfil Inovação buscado procura assegurar uma formação que provoque o desenvolvimento da aplicação da criatividade do estudante, sendo este capaz de protagonizar mudanças nas empresas, no desenvolvimento e na condução de projetos internacionais inovadores. O perfil Interculturalidade busca proporcionar ao estudante uma experiência em diferentes situações interculturais, entre elas: a mobilidade internacional durante sua formação; a construção do domínio de línguas estrangeiras; o conhecimento e a interação no contexto de diferentes culturas; a vivência de inserção em projetos internacionais e sua imersão em redes internacionais, pessoais, acadêmicas ou profissionais.

A UTC mostrou-se interessada em desenvolver e implementar o projeto em cooperação com a UTFPR. Ficou estipulado que os escritórios internacionais das duas universidades seriam os responsáveis pela estruturação dos limites da proposta e pela definição das estratégias de trabalho. $\mathrm{Na}$ sequência, os grupos de trabalho, na UTC e na UTFPR, foram configurados. Esses grupos revisaram a literatura com o objetivo de conhecer o estado da arte do ensino da engenharia e depois projetar possibilidades de ensino para os próximos 20 anos (de 2015 até 2035). O grupo se encontrou virtualmente e regularmente para tratar de assuntos-chave relacionados à viabilização do Programa (CZIULIK et al., 2016).

A ideia inicial do Programa Engenheiro 3i foi discutida e formatada durante uma sequência de quatro encontros envolvendo equipes de ambas as instituições. O primeiro encontro presencial para tratar da proposta aconteceu em Compiègne, de 3 a 5 de fevereiro de 2016. No encontro, três conclusões foram estabelecidas: (i) há uma necessidade de melhor preparar os estudantes para a complexidade e a heterogeneidade dos ambientes contemporâneos; (ii) há a necessidade de identificar as competências relacionadas ao saber, ao saber-fazer e ao saber-ser nos estudantes a partir de situações/problemas reais; e (iii) há a necessidade de uma cooperação pedagógica estreita entre os parceiros do Programa para identificar módulos e cenários inovadores de formação (RAMOND, 2017).

A formação complementar de um profissional diferenciado é uma preocupação do Programa Engenheiro 3i. Por isso, ele foca na exigência de um profissional com mentalidade dinâmica, intercultural, com domínio de três línguas, com experiência de estágio em empresa presente na França e no Brasil, com senso de trabalho em equipe para resolver problemas reais, de interesse da indústria, usando meios variados, com equipe multicultural, presencial e a distância (UTFPR, 2017).

Tem-se, no início do Programa Engenheiro 3i, na perspectiva da internacionalização, uma conexão de sistemas educacionais integrados com relações universitárias acontecendo além da nação (MARGINSON; RHOADES, 2002).

Como perspectiva desse primeiro encontro, ficou decidida a continuidade dos trabalhos, com aprofundamento nas competências, nos módulos e nos cenários de formação, e ficou definido como tarefa a criação de um percurso de formação inovador, com implantação progressiva dos módulos específicos para um programa de duração de 3 anos.

O segundo encontro aconteceu no Brasil, em Curitiba, entre 29 e 30 de setembro de 2016, na Federação da Indústria do Estado do Paraná. Nesse encontro foram discutidas as perspectivas apontadas no encontro anterior. As competências para o perfil do Engenheiro 3i foram lançadas. Ficou estabelecido que o egresso deveria ser capaz de: gerenciar projetos internacionais, dominar ferramentas colaborativas, dominar aspectos não técnicos, adaptar produtos e processos a outras culturas, demonstrar atitudes empreendedoras em ambientes internacionais, propor soluções sistemáticas para problemas de engenharia, adaptar soluções para o contexto heterogêneos, propor projetos para captação de recursos internacionais, compreender os diferentes mecanismos de propriedade intelectual em contexto internacional, propor soluções criativas em projetos de engenharia. Para a formação inovadora, o grupo pensou em módulos de disciplinas, Escola de Verão, Ateliê Projeto (AP) Internacional, miniprojeto 
envolvendo adaptação de produto em contexto intercultural, curso de línguas durante o estágio internacional, estágio internacional de seis meses, imersão de um mês em startup ou incubadora, intercâmbio, entre outros (RAMOND, 2017).

O que se percebe é a construção de um programa de mobilidade traçado a partir de um perfil de estudante de engenharia que se quer construir. A estruturação desse programa corresponde à proposição de uma política de mudança e desenvolvimento no ensino superior defendida pela Unesco, que destaca a importância dos elementos que devem ser estruturantes na internacionalização da educação superior.

\begin{abstract}
XX. A internacionalização do ensino superior é, antes de mais nada, uma reflexão de caráter universal do aprendizado e da pesquisa. É reforçada pelos procedimentos correntes de integração econômica e política, assim como pela necessidade crescente de entendimento intercultural. A expansão do número de estudantes, professores e pesquisadores que trabalham, vivem e se comunicam num contexto internacional atesta essa tendência. A considerável expansão de vários tipos de redes e outros tipos de ligação entre as instituições, professores e estudantes é facilitada pelo avanço contínuo da informação e das tecnologias de comunicações. XXI. A cooperação internacional deve ser baseada, antes de mais nada, na parceria e na busca coletiva pela qualidade e relevância do ensino superior. As condições de deterioração nas quais os institutos de ensino superior funcionam, particularmente em alguns países em desenvolvimento, requerem solidariedade internacional. A esse respeito, é importante promover programas e trocas que possam contribuir para reduzir os desequilíbrios existentes e facilitar o acesso à transferência de conhecimento (UNESCO, 1999, p. 17, grifo do autor).
\end{abstract}

As críticas que os processos de internacionalização têm sofrido, sobretudo aquelas que estão relacionadas ao modo assimétrico de subserviência que países periféricos têm em relação aos países mais desenvolvidos (NÓBREGA, 2014), podem ser diminuídas ao se ter uma relação bilateral entre as instituições envolvidas.

O terceiro encontro aconteceu em Compiègne, na UTC, na semana de 02 a 06 de outubro de 2017. Representantes da UTFPR e da UTC discutiram as competências que deveriam ser trabalhadas no aluno e os módulos que contemplariam essas competências, um exercício de verificação do que cada instituição ofertaria. Como resultado, uma matriz inicial completa do Programa foi definida. As referências das competências, o catálogo de módulos e de créditos para validação, a matriz cruzada entre habilidade e módulo e as regras de validação do certificado foram lançados (RAMOND, 2017). As discussões do grupo levaram a estipular quatro famílias de competências: 1) participar dos projetos dos 3i; 2) conceber e inovar; 3) conhecer o contexto local e internacional; e 4) dominar as situações comunicativas em contexto dos $3 \mathrm{i}$ (RAMOND, 2017).

A primeira família de competências está relacionada à capacidade do egresso de engenharia: em adquirir, capitalizar e compartilhar conceitos básicos em gerenciamento de projeto; de se integrar com uma equipe intercultural (e interorganizacional); de contribuir para a realização técnica, inovativa e de gerenciamento de projetos; de ter a capacidade de escolher, dominar e utilizar métodos e ferramentas colaborativas de gestão, de técnica e de comunicação; de adaptar métodos e ferramentas ao contexto local e internacional; e de participar de projetos interdisciplinares dentro do quadro de funcionários da empresa parceira no programa.

A segunda família de competências diz respeito à capacidade do futuro engenheiro: de gerar ou adaptar um produto a diferentes culturas e ao contexto; de integrar a dimensão durabilidade na concepção do produto e nas soluções propostas, considerando ecodesign, transição de energia, economia circular, entre outros; de saber fazer emergir a inovação na dinâmica de um grupo intercultural; de pensar a inovação como motor do desenvolvimento e em sintonia com a evolução da sociedade; e de inovar em um contexto de codesenvolvimento e de parceria internacional, conhecendo contratos, propriedade intelectual, legislação, entre outros.

A terceira família de competências está relacionada à capacidade do futuro profissional engenheiro de: conhecer o contexto local e internacional; capitalizar, articular e explorar os conhecimentos para a inovação; decifrar uma estratégia de negócios dentro da empresa em contexto internacional; compreender as normas e regulamentos em nível local, nacional e internacional; conhecer 
os programas de financiamento nacionais e internacional; e compreender o contexto histórico, ético, sociocultural, político, econômico e administrativo dos países envolvidos na parceria.

A quarta família de competências busca oferecer ao estudante de engenharia: a oportunidade da prática do idioma do país anfitrião e do inglês, de dominar a comunicação intercultural na compreensão de que esse aluno precisa saber ser, negociar, gerir conflitos, distanciar, descentralizar, entre outros; possibilidades para identificar e levar em consideração os perfis psicológicos e as motivações pessoais no gerenciamento de projetos e saber como comunicar um projeto com recursos e suportes adaptados a diferentes tipos de público, como aos que tomam decisão, ao público em geral ou ao de engenheiros. A descrição dessa fase de construção do Programa Engenheiro 3i é um exemplo de como a internacionalização da universidade pode acontecer inversamente à ideia de internacionalização impulsionada pela categorização da educação como serviço, com regulamentação da World Trade Organization, e adotada gradativamente pela concepção de transnacionalização frente à soberania do Estado-nação.

O encontro seguinte, o quarto, aconteceu em Curitiba, na UTFPR, entre os dias 20 e 24 de novembro de 2017. Na ocasião, o edital da Chamada de seleção para o Programa Engenheiro 3i (UTFPR, 2017) já havia sido divulgado. O objetivo do quarto encontro foi de validação, junto às indústrias instaladas na Região Metropolitana de Curitiba, das famílias de competências construídas no contexto das discussões entre as duas universidades, de definição das regras de validação do certificado do Engenheiro 3i, e formatar a dinâmica do AP Internacional e da Escola de Verão, que aconteceria em fevereiro de 2018, em Curitiba, para os alunos selecionados no Brasil e na França para o Programa.

Tanto para o aluno brasileiro como para o francês, o Programa Engenheiro 3i configura-se, portanto, como uma oportunidade de aprimoramento e de certificação complementar à formação regular dos cursos de engenharia, com um reforço na mobilidade internacional para validar as exigências das competências 3i. A validação acontece por módulos das Ciências Humanas e de Linguagens, existentes nas instituições parceiras e por módulos novos na forma de seminários e APs internos e externos (RAMOND, 2017). O tempo para certificar um aluno Engenheiro 3i é estimado em três anos. Para a primeira turma ficou definida a obrigatoriedade de aprovação nos módulos durante os seis primeiros semestres do Programa.

O Programa Engenheiro 3i se desenvolve em paralelo ao curso de graduação, ou seja, caso o aluno se gradue em engenharia durante o desenvolvimento do Programa, ele poderá obter a certificação Engenheiro 3i, finalizando o projeto dentro de uma empresa ou mesmo com estágio de um ano no estrangeiro. Também será possível validar atividades fora das universidades parceiras por meio de conferências, seminários, cursos. Ficou estipulado que as regras de validação do diploma devem ser compatíveis com as regras de validação do diploma de engenharia da UTC e da UTFPR.

Para um aluno do Brasil ou da França ter a validação de Engenheiro 3i agregada ao diploma de engenharia é necessário ser aprovado em todos os módulos e, obrigatoriamente, vivenciar a mobilidade internacional em dois semestres, um de aula e outro de estágio. O participante vivenciará a permanência e o estágio em empresa do setor industrial, sendo que dos dois estágios obrigatórios em empresas, pelo menos um deles deverá ser no estrangeiro, com o parceiro do Engenheiro 3i. A validação do certificado 3 i exige a permanência, curta ou longa, do aluno em uma startup ou em um projeto livre, ligado a uma startup existente. Outra exigência é a participação do aluno em projetos e na disciplina AP Internacional, nos quais estudantes do Brasil e da França trabalham em equipe a distância, durante um semestre, cujo pré-requisito é a realização de disciplina voltada à Gestão de projetos.

Ainda fazem parte dos critérios de validação um relatório final e a participação do estudante em 15 horas de curso, escolhidas entre os módulos ofertados pelo catálogo de cursos do Engenheiro $3 \mathrm{i}$ ou fora dele, em forma de seminário ou conferências sobre temas variados, como desenvolvimento sustentável, economia circular, controle de tecnologia e gerenciamento de conhecimento em contexto 3i, economia local, comunicação científica ou profissional em inglês, interculturalidade, edição e financiamento de projetos e gerenciamento avançado de projetos (RAMOND, 2017).

A validação também está condicionada ao critério Interculturalidade e ambiente internacional. Assim, para que o estudante obtenha a certificação Engenheiro 3i precisará frequentar pelo menos uma disciplina na área intercultural, outra disciplina que contemple os assuntos relacionados à empresa estrangeira e ainda seminários sobre o conhecimento do contexto econômico local, seja em 
Curitiba (Brasil) ou em Compiègne (França). Ao fim do Programa, o estudante deve comprovar domínio em línguas no nível C1 em inglês e na língua do país estrangeiro, isto é, o português para os alunos da França e o francês para os alunos do Brasil. Para atingir esse nível, o Programa previu acompanhamento do estudante por meio dos setores do ensino de línguas das universidades envolvidas.

As exigências de domínio de línguas seguem marcas das Universidades de Tecnologia da França, em que a comunicação do engenheiro é fundamental no idioma inglês e no idioma estrangeiro, ou seja, o Programa Engenheiro 3i é trilíngue. Para os acadêmicos do Brasil, embora seja prevista aula intensiva de francês, é necessário, para se inscrever, comprovar o conhecimento em francês e inglês no mínimo no nível B1, segundo o Quadro Europeu de Referência. Para os estudantes da França a comprovação desse nível se dá no idioma inglês e português. A exigência foi pensada para agilizar o desempenho comunicacional do estudante, pois, partindo do ponto inicial B1, o aluno já tem independência comunicativa, mesmo que intermediária, em situação de sala de aula ou de estágio na empresa parceira da cooperação. O aluno entenderá os principais pontos do assunto, com capacidade de expressar seu pensamento em eventos concretos e prováveis, nos tempos verbais que remetem ao passado, ao presente e ao futuro, podendo opinar, ainda que de forma limitada, em algumas situações que exigem discurso argumentativo e raciocínio lógico. Conseguirá, ainda, descrever situações e lidará com ocorrências quotidianas de modo fácil.

O estudo de línguas na UTC é parte da formação do engenheiro. De toda a formação, 33\% é de disciplinas da área de humanidades e de línguas. Um estudante recém-chegado é instruído pelo guia do estudante a frequentar no máximo três línguas simultâneas durante o período de tronco comum (tronc commun), o equivalente a quatro semestres, e aprofundá-las, deixando espaço para as outras disciplinas de humanidades. Os estudantes da UTC podem escolher entre oito idiomas, entretanto, o francês, como língua estrangeira, não é ofertado para o acadêmico nativo (UTC, 2020). Na UTFPR, o ensino de línguas também é ofertado. Todos os campi têm um Centro Acadêmico de Língua Estrangeira Moderna (CALEM), porém, a frequência do acadêmico não é parte integral dos cursos, como na UTC. O idioma inglês é ofertado nos treze campi gratuitamente. Contudo, para outros idiomas, como o francês, o espanhol, o italiano, o alemão, e o japonês, há a oferta em alguns campi e noutros não (CECHIN, 2019).

Antes de elaborar o primeiro edital do Programa, os organizadores escolheram uma empresa automobilística presente no Brasil e na França para os alunos desenvolverem uma atividade, buscando solucionar um problema real dentro da indústria. A empresa escolhida tem filial em Curitiba e é parceira da UTC há muitos anos.

O primeiro edital da UTFPR para o Programa Engenheiro 3i ofertou seis vagas para os alunos da UTFPR Campus Curitiba, envolvendo os cursos de Engenharia Civil, de Computação, de Controle e Automação, Elétrica, Eletrônica, Mecânica e Mecatrônica (UTFPR, 2017). Cinco alunos foram selecionados. A UTC também abriu seis vagas. Foi feita uma chamada pública para a inscrição. Dos inscritos, a comissão responsável selecionou sete alunos dos cursos de Engenharia Informática, Mecânica, Sistemas Mecânicos e Sistemas Urbanos, enquanto optou por excluir da lista os alunos dos cursos de Engenharia Biológica e de Processos, pois o seu perfil teria pouca aplicação na empresa automobilística. Outro critério aplicado aos selecionados na primeira fase foi ter conhecimento de língua portuguesa. Sete candidatos restaram em igual nível. A comissão analisou e decidiu criar uma vaga adicional. Cabe salientar que a parte francesa do Programa (UTC) buscou e obteve recursos, até junho de 2018, da Sorbonne Universités (grupo de universidades da qual a UTC faz parte) para atividades desenvolvidas no Programa Engenheiro 3i.

A seleção dos candidatos parte de um perfil discutido por uma comissão das duas instituições. As exigências de domínio de línguas é fundamental. Outra característica diz respeito ao critério que trata da vivência e do tempo do estudante no meio acadêmico. O tempo para se acostumar com a vida universitária e consolidar um padrão de estudos dificilmente se efetiva no primeiro ano de curso (SOUZA et al., 2020). Um aluno maduro, acostumado com a rotina universitária, é, normalmente, no Brasil, um acadêmico do sexto ou sétimo período do curso. O critério pressupõe que o aluno, cursando mais de $50 \%$ do tempo total do curso, esteja preparado para o desafio do engenheiro do futuro, nos moldes pensados pela UTFPR e UTC. Para as atividades planejadas na cooperação, são fundamentais alunos já inseridos na cultura universitária, acostumados a uma rotina que exige gerência de tempo e hábitos de estudos já avançados. 
O perfil de estudante selecionado aumenta a probabilidade de sucesso nas atividades que foram pensadas para o Programa. Caso o aluno não atinja o desempenho esperado, não sendo aprovado em alguma disciplina na França ou no Brasil, ou tenha algum problema disciplinar ou comportamental, não permanecerá no Programa Engenheiro 3i e, ainda, mesmo que tenha sido selecionado por algum edital de dupla diplomação (UTFPR, 2021), será interditado de continuar seus estudos na UTC ou na UTFPR.

Outro critério utilizado foi o coeficiente de rendimento escolar que deveria ser igual ou superior a 0,7 (zero vírgula sete), nos padrões da UTFPR, que corresponde ao grupo dos $25 \%$ melhores alunos.

No início de 2018, foi implementado o piloto do Programa Engenheiro 3i com a realização da Escola de Verão, que aconteceu entre os dias 05 e 16 de fevereiro de 2018. Durante duas semanas, os estudantes se conheceram e vivenciaram atividades de imersão cultural. Também foram apresentados dois seminários sobre interculturalidade, um por uma pesquisadora no tema e outro por representante de uma indústria multinacional, bem como seminários sobre inovação. Além disso, os estudantes tiveram a oportunidade de trabalhar durante três dias no Centro de Criatividade da indústria parceira. Nesses três dias, os estudantes conviveram com profissionais da indústria que atuavam no tema de estudo do projeto piloto e que era o foco da atividade da AP Internacional. Ainda na Escola de Verão, os estudantes, acompanhados pelos professores de ambas as universidades (três da UTC e quatro da UTFPR), definiram as estratégias de trabalho e os papéis de cada um no grupo, para a realização da atividade a distância durante o primeiro semestre de 2018. A atividade AP pressupõe a autonomia na gerência do projeto dos estudantes. Isso significa que lhes cabe gerenciar orçamento, distribuir funções, programar e administrar tarefas, ferramentas técnicas e colaborativas, pensar a logística, a comunicação, elaborar o relatório intermediário e o final, entre outras atividades. Os supervisores, professores e/ou pessoas da indústria desempenham um papel de aconselhamento ou de consultoria de negócios ou de projetos.

Em julho de 2018, aconteceu a apresentação dos projetos pelos alunos e as equipes dos gestores do Programa avaliaram a primeira edição do Programa Engenheiro 3i (RAMOND, 2017). O Programa Engenheiro 3i teve continuidade nos anos de 2019 e 2020, com a realização das Escolas de Verão, nos respectivos meses de fevereiro, e da atividade AP Internacional, à distância, no período de março a junho de cada ano. No ano de 2019, houve a participação de cinco estudantes franceses e oito brasileiros, além de quatro professores franceses e dez professores brasileiros. Os estudantes de diferentes modalidades da engenharia e os professores se dividiram em dois grupos. Um primeiro grupo, formado por quatro estudantes do Campus Ponta Grossa e dois franceses, desenvolveu um projeto de otimização da linha de produção de motores de uma indústria de caminhões da empresa DAF. O segundo grupo, formado por quatro estudantes brasileiros e três franceses, debruçou-se no desenvolvimento de um modelo gravitacional do fluxo de transporte da cidade de Curitiba, junto ao Instituto de Pesquisa e Planejamento Urbano de Curitiba (IPPUC).

Já no ano de 2020, o programa foi desenvolvido com a participação de oito estudantes franceses e nove brasileiros, e três professores franceses e dez professores brasileiros, novamente distribuídos em dois grupos. O grupo de Ponta Grossa atuou no desenvolvimento de um aplicativo web para a otimização de linha de produção, junto à DAF. No caso do grupo de Curitiba, na nova oportunidade de atuação em parceria com o IPPUC, propôs um Plano de Desenvolvimento Sustentável para o Bairro do Umbará. Em todos os casos, os resultados finais foram apresentados e entregues aos parceiros (DAF e IPPUC), sendo devidamente elogiados por ambos. Pode-se afirmar que a edição do ano de 2020 mostrou uma evolução no funcionamento do programa (seleção dos estudantes, contatos com parceiros do mundo real, realização e acompanhamento da pesquisa internacional a distância). Isso demonstra que as experiências anteriores foram devidamente consideradas e capitalizadas para esse aprimoramento. Todos os estudantes brasileiros envolvidos no projeto partiram para a França, alguns para um intercâmbio de um ano (um semestre de estudo e um de estágio industrial) e outros para dois anos, para obtenção da dupla diplomação (três semestres de estudos e um de estágio industrial). Com a pandemia de covid-19, o programa não operou em 2021. Planeja-se retomá-lo em 2022. 


\section{PROGRAMA CAPES/BRAFITEC}

O Programa Brafitec nasceu em 25 de abril de 2002 a partir de uma experiência de três anos de mobilidade de alunos do Brasil para a França. O Programa surgiu com uma proposta, à época inovadora e ousada, para um engenheiro do século que se iniciava, por meio da mobilidade durante a graduação com acompanhamento da instituição (GROCHOCKI, 2016a). Nesse Programa, o aluno sai do país de origem já com um plano de trabalho, sabendo que as disciplinas que cursará serão convalidadas na instituição de origem no Brasil. Tem apoio financeiro de deslocamento e permanência no país estrangeiro - no caso, França e Brasil (UTFPR, 2018). Foca num engenheiro bilíngue com experiência de estágio dentro da indústria na França. Além disso, o programa envolve a mobilidade das equipes gestoras do Projeto nas instituições dos dois países.

Algumas características do Brafitec evidenciam a venda de um modelo francês de educação. O fato de a educação ser commodity foi visto por Wit (2013) em uma lista que identifica um conjunto de problemas inerentes ao processo de internacionalização. Entre os problemas está o discurso da internacionalização, muitas vezes dissociado da realidade e concebido nos termos pouco abrangentes da antiga educação internacional: a globalização, a intensificação do tratamento do ensino como commodity e a noção de uma economia e uma sociedade global do conhecimento que transformaram a internacionalização num produto, por vezes conflitante com o seu discurso; o fato de a internacionalização estar muito pautada em números (entrada e saída), em detrimento de resultados, e de pouca atenção ser dedicada às normas, valores e princípios éticos da prática da internacionalização; além de a internacionalização ser pensada ainda na forma de um processo que envolve países, desconsiderando a relação entre culturas e entre o global e o particular.

O modelo atual do Programa Brafitec começou em 1997, com outro nome, e foi sendo melhorado até 2001, quando aconteceu o lançamento do Programa de Formação Integrada nas Escolas Francesas de Engenharia de Aluno-Engenheiros Brasileiros. O Programa Brafitec foi uma demanda brasileira, articulada pela CAPES e organizada na França pela Conférence des Directeurs des Écoles Française d'Ingénieurs (CDEFI), destinado apenas aos cursos de Engenharia em nível de graduação, com o objetivo de estimular o intercâmbio entre as IES brasileiras e francesas e de aproximar as estruturas curriculares, inclusive a equivalência e o reconhecimento mútuo de créditos obtidos nas instituições participantes (CAPES, 2017).

Na fase inicial, o Programa previa, para os anos de 1999, 2000 e 2001, três edições de cem alunos, para formação na França. O objetivo era “[...] criar novos laços entre universidades brasileiras e escolas francesas de engenheiros" (GELAS, 2009, p.2).

O nome Brafitec foi adotado em 2002, quando as experiências da fase inicial passam a ofertar suporte para uma proposta mais bem estruturada e com um novo formato. Foi criado um guia de encargos e um edital lançado para todos os estabelecimentos envolvidos no projeto no Brasil e na França, com edições previstas a cada dois anos. Os projetos de parceria entre as instituições começaram a ser avaliados por especialistas dos dois países, um Comitê de pilotagem misto e uma coordenação no Brasil e uma na França (GELAS, 2009).

O edital foi lançado pela CAPES e aberto para todas as universidades brasileiras. Do lado francês, acontece o mesmo, é aberto para várias universidades do país.O registro do primeiro projeto CAPES/Brafitec no Brasil (n. ${ }^{\circ}$ 001/2003) envolveu três IESs: Centro Federal de Educação Tecnológica do Paraná (CEFET-PR), Pontifícia Universidade Católica do Paraná (PUCPR) e Universidade Federal do Paraná (UFPR) - em parceria com a Universidade Tecnológica de Compiègne (UTC), Universidade Tecnológica de Troyes (UTT) e Universidade Tecnológica de Belfort-Montbéliard (UTBM). Em 2016, estavam envolvidas 53 IES brasileiras e 54 francesas (GROCHOCKI, 2016a). De 2003 até 2018, 8.897 alunos participaram do Programa no sentido Brasil/França e 2.936 alunos no sentido França/Brasil (GELAS, 2019).

O edital mais recente para as universidades brasileiras participarem é o de n. ${ }^{\circ} 13 / 2019$. Uma característica do Brafitec é que a mobilidade bilateral acontece com o estudante e com docentes das equipes do Brasil e da França, entretanto, com a pandemia de covid-19, a mobilidade para o ano de 2021 foi adiada para o mês de setembro (CCS/CAPES, 2020). 
Depois que a CAPES lança o edital para as universidades se inscreverem no Programa Brafitec, cabe a cada universidade cadastrada lançar seu edital para selecionar os alunos no Programa. O número de vagas é estipulado pela CAPES. Para uma IES participar do Brafitec, precisa apresentar um projeto, que pode ou não envolver outra IES, sendo que o máximo de instituições envolvidas são três. A proposta deve ter: um plano de trabalho conjunto entre as universidades do Brasil e da França; um planejamento de dois anos para as atividades (permite prorrogação da proposta por mais dois anos); um coordenador com o título de doutor, obtido há, pelo menos, quatro anos, para cada IES contida na proposta; uma equipe de trabalho com dois doutores, no mínimo; e, ainda, a IES onde atua o coordenador deve estar vinculada a um Programa de Pós-graduação reconhecido e recomendado pelo MEC.

O perfil exigido do candidato, para se inscrever no Programa Brafitec no Brasil, abrange os seguintes quesitos: estar entreo sexto e o oitavo período do curso, ter obtido no mínimo 600 pontos no Exame Nacional de Ensino Médio (Enem), realizado a partir de 2009, e integralizado no mínimo 40\% e no máximo $80 \%$ do currículo previsto para seu curso. Também deve estar regularmente matriculado em um curso de Engenharia e apresentar comprovante de proficiência B1 em língua francesa, certificado por testes reconhecidos internacionalmente (UTFPR, 2018). Além disso, o aluno precisa ter coeficiente de rendimento escolar igual ou superior a 0,7 (zero vírgula sete) e não pode ter mais de três reprovações no percurso acadêmico de ensino superior, consideração feita para o curso atual do estudante e outros cursos, caso o mesmo tenha solicitado transferência.

Na UTFPR, participam, em média, três alunos por ano no Brafitec, exceção feita em 2011, quando nove alunos participaram. Essa foi a fase que o Brafitec e o Programa Ciências sem Fronteiras tiveram parceria.

O Brafitec sentido Brasil/França prevê três tipos de apoios financeiros: a Missão de Trabalho, que diz respeito à ajuda de custo para membros do projeto; a Missão de Estudo, que se refere ao estudante; e o Material de Custeio, que trata de recursos concedidos por ano e por projeto para despesas com aquisição de material de consumo. São duas Missões de Trabalho ao ano e por projeto. Cada missão não pode ser inferior a sete dias e também não pode ser superior a 20 dias. O coordenador do projeto é o único que poder realizar a Missão de Trabalho em anos consecutivos. Membros da equipe têm intervalo de dois anos para participar de uma Missão de Trabalho. A Missão de Estudo trata de despesas como bolsa no exterior, auxílio instalação, seguro-saúde, adicional de localidade, auxílio material didático e auxílio deslocamento. Está incluído nesse item o financiamento de aulas de francês, caso a IES francesa considere necessário. Nesse caso, a CAPES financia a Français Langue Étrangère (FLE) para alunos nos níveis A1, A2 e B1. Para os níveis A1 e A2, o financiamento pode ser de até dois meses de curso FLE e, para o nível B1, o tempo máximo é de um mês. Já o Brafitec sentido França/Brasil prevê apenas um tipo de apoio financeiro: a bolsa de estudo mensal, que pode ser por um período mínimo de quatro meses e máximo de dez meses.

O Programa Brafitec prevê também que aconteça, a cada ano, o Fórum Brafitec, alternando a sua sede entre o Brasil e a França. O objetivo do Fórum é o encontro entre coordenadores dos projetos e as equipes gestoras do Programa em ambos os países, para avaliação e aperfeiçoamento contínuo do Programa.

\section{PROGRAMA ENGENHEIRO 3i X BRAFITEC}

A internacionalização de uma universidade pode acontecer com a presença de estudantes da instituição parceira no campus, com a realização de pesquisas e produção de patentes de forma conjunta, com a cooperação acadêmica, com a existência de mecanismos de compatibilidade curricular, com a mobilidade docente, entre outras possibilidades (BARTELL, 2003). O quadro 1 mostra o comparativo entre o Programa Engenheiro 3i e o Programa Brafitec quanto aos países envolvidos, às instituições participantes, aos cursos envolvidos, ao financiamento ofertado, às exigências do idioma, ao trabalho em equipe, à presença de empresa parceira, ao conteúdo e à certificação. 
Quadro 1: Comparativo entre o Programa Engenheiro 3i e o Programa Brafitec

\begin{tabular}{|c|c|c|}
\hline & $\begin{array}{l}\text { PROGRAMA ENGENHEIRO } \\
\text { 3I }\end{array}$ & PROGRAMA BRAFITEC \\
\hline Instituições participantes & UTFPR e UTC & CAPES, Brasil e CDEFI, França \\
\hline Cursos envolvidos & Cursos de Engenharia & Cursos de Engenharia \\
\hline Financiamento ofertado & $\begin{array}{c}\text { Financiamento apenas no lado } \\
\text { francês }\end{array}$ & $\begin{array}{l}\text { Financiamento no lado francês e } \\
\text { brasileiro }\end{array}$ \\
\hline Exigências do idioma & $\begin{array}{l}\text { Exigência inicial B1 em Português } \\
\text { ou Francês e Inglês e final C1 em } \\
\text { Francês, Português e Inglês }\end{array}$ & $\begin{array}{c}\text { Exigência inicial B1 no Francês e } \\
\text { Português }\end{array}$ \\
\hline Trabalho em equipe & Faz parte da proposta do Programa & $\begin{array}{c}\text { Não faz parte da proposta do } \\
\text { Programa }\end{array}$ \\
\hline Presença de empresa parceira & Faz parte da proposta do Programa & $\begin{array}{c}\text { Não faz parte da proposta do } \\
\text { Programa }\end{array}$ \\
\hline Conteúdo do programa & $\begin{array}{l}\text { Pré-estabelecido, adicional às } \\
\text { atividades regulares da formação do } \\
\text { engenheiro }\end{array}$ & $\begin{array}{c}\text { Atividades curriculares previstas nas } \\
\text { instituições parceiras }\end{array}$ \\
\hline Certificação & Certificação Engenheiro $3 \mathrm{i}$ & Não certifica \\
\hline
\end{tabular}

A partir do quadro acima, as similaridades se resumem ao fato de ambos os programas se desenvolverem no âmbito da cooperação internacional Brasil-França e de serem focados na formação internacional do engenheiro.

Quanto às diferenças, tem-se que o Programa Engenheiro 3i acontece no nível de relação, de convênio entre duas universidades, a UTFPR e a UTC, enquanto o Programa Brafitec é resultado de um convênio em nível ministerial envolvendo a CAPES/Brasil e a CDEFI/França, aberto para várias universidades e cursos de engenharia do Brasil e da França. Uma outra diferença diz respeito ao financiamento. O Programa Engenheiro 3i, nessa primeira edição, teve financiamento integral para o estudante apenas no lado francês. No lado brasileiro, o participante arca com a maioria das despesas. Já o Brafitec tem financiamento integral tanto para os alunos brasileiros como para os franceses. Ressaltase que a seleção do Programa Engenheiro 3i (período 2018/2020), no lado brasileiro, selecionou dois estudantes já contemplados pelo Programa Brafitec. Assim, esses acadêmicos participarão dos dois programas, sendo que a bolsa do Brafitec ajudará na manutenção do estudante na UTC enquanto ele participa também do Programa Engenheiro 3i.

Ainda focando-se nas diferenças, quanto às exigências em relação ao idioma do país anfitrião (português ou francês), a inscrição exige nível B1, do Quadro Europeu Comum de Referência, para ambos os Programas. Porém, para o Programa Engenheiro 3i, acresce-se a esses idiomas o inglês. Para o Programa Engenheiro 3i, há a exigência de comprovação do nível B1 em inglês, no início, e C1, na língua estrangeira e no inglês, ao fim do programa.

Outra diferença está na especificação do trabalho em equipe. No Programa Engenheiro 3i, os alunos selecionados no ano trabalham em parceria com os colegas do mesmo país e com os colegas do país parceiro, explorando plataformas e meios de interação simultânea e a distância para resolver uma situação/problema real, comum ao grupo apresentado no AP. No Programa Brafitec não há essa característica legitimada no programa, pois o aluno tem um percurso acadêmico solitário, embora trabalhe em equipe nas atividades propostas pelas disciplinas.

No trabalho em equipe é que se evidencia características universitárias que se fortalecem a partir da metade do curso: autonomia, gerencia adequada do tempo, responsabilidade nas tarefas a serem cumpridas, percepção das consequências de realizar ou não as atividades, por exemplo. Para a UTC, a compreensão de que a maturidade acadêmica do aluno é uma construção pessoal adquirida ao longo do curso vem desde a fundação, em 1974. Por ser a primeira universidade de tecnologia da França, o modelo proposto para a formação do estudante da universidade de tecnologia deveria ser diferenciado da universidade clássica e das escolas de engenharia à época (LEQUIN, 2015). O entendimento de que o estudante, ao entrar na UTC, ainda era imaturo e precisaria conhecer os vários ramos da engenharia, uma vez que a UTC diploma exclusivamente engenheiros, fez com que as disciplinas - chamadas de Unidades de Valor (UV) - fossem organizadas como um menu, em que nos dois primeiros anos o estudante transita 
no troco comum, conhecendo as várias possibilidades de atuação da engenharia, para, depois, escolher um ramo específico, quando estiver mais maduro (CECHIN; PILAT'TI; RAMOND, 2020). A compreensão da UTC e da UTFPR de que existe um tempo para o estudante entender a rotina universitária é importante para atuar no Programa Engenheiro 3i.

Os programas também são diferentes no que diz respeito à participação de empresas no processo. No Programa Engenheiro 3i, elas são parte, atuando no Brasil e na França, e também acompanham os dois grupos de alunos nos dois países. Já no Programa Brafitec não há uma empresa parceira fazendo parte do Programa e nem acompanhando o percurso do aluno. O que o Programa Brafitec pode contemplar é a atividade de estágio em empresa no exterior, não necessariamente com inserção em ambos os países.

Ainda como ponto diferente, tem-se o aspecto do conteúdo dos mesmos. No programa Engenheiro 3i é previsto um percurso específico, complementar e parcialmente adicional à formação regular do engenheiro em ambos os países. O Programa Brafitec está fundamentado na realização de atividades curriculares previstas nas instituições parceiras nos projetos.

Como última diferença, o Programa Engenheiro $3 i$ certifica o aluno participante, diferenciando-o no mundo do trabalho de outros estudantes que não participaram de programas de mobilidade internacional ou que participaram de programas convencionais como o proposto pelo Programa Brafitec.

O cotejo entre o Programa Engenheiro 3i e o Brafitec evidencia aspectos de um e de outro programa, de modo a se confirmar que é possível programas de mobilidade aperfeiçoarem a internacionalização da universidade e responderem positivamente às principais críticas do processo de internacionalização do ensino superior, como o desenvolvimento da internacionalização como fator de imposição dos valores do neoliberalismo e de determinadas culturas, a comercialização da educação e a imposição do domínio da língua inglesa e do modelo tradicional de universidade (BARBOSA; NEVES, 2020; LIMA; MARANHÃO, 2011).

Programas como o Engenheiro 3i e o BRAFITEC tornam a internacionalização um meio para obter um resultado e não um fim em si. Wit (2013) afirma que o conceito a ser resgatado é o de que "a internacionalização é uma estratégia para aprimorar a qualidade do ensino e da pesquisa", e os programas cotejados respondem qualitativamente a esse conceito.

As universidades brasileiras, notadamente as públicas, na direção da internacionalização, apesar de poucas exceções, como a USP e a Unicamp, apresentam limitações importantes para a internacionalização. Entre os desafios estão: internacionalizar-se para dialogar com o mundo; o uso da língua inglesa, principalmente na oferta de disciplinas; a diminuição da burocracia, legal e institucional, que impõe morosidade e amarras ao sistema público como um todo; superar limitações legais para o recrutamento de pesquisadores do exterior; a proteção do tempo do pesquisador; a pouca tradição das universidades brasileiras; o financiamento; a falta de infraestrutura; o baixo impacto da produção científica; a falta de meritocracia na carreira docente; a carga de trabalho docente elevada; o número reduzido de convênios com instituições de ponta que abarquem pesquisas conjunta e mobilidade (ESCOBAR, 2013). O quadro é, em muito, agravado pela falta de planejamento estratégico do Estado e pelo desmonte das universidades públicas em curso.

Apesar de os programas apresentarem uma resposta positiva para muitos gargalos da internacionalização das universidades, eles ainda podem ser melhorados. No que se refere à questão racial, por exemplo, os programas aqui tratados não reservam vagas para raça específica alguma ou grupo social. No caso brasileiro, não há vagas para a raça menos privilegiada no país que seria a afrodescendente e, para a realidade francesa, seriam pessoas assistidas por programas nacionais de apoio à moradia, alimentação, cultura e lazer. Outra questão é o fato de os editais dos programas partirem de um perfil bastante elitista de candidatos. Isso na realidade francesa pode ser menos desigual, mas, no Brasil, elimina muitos candidatos. Entretanto, há de se considerar que três de cada quatro estudantes que estão nas universidades públicas têm renda mensal familiar per capita de até 1,5 salário mínimo (ANDIFES, 2019).

A natureza dos programas comparados é muito distinta. O Brafitec é um programa entre países e sua mobilidade ocorre, principalmente, na direção do Brasil para a França. O Engenheiro 3i é um programa entre duas instituições que vivenciaram e aprenderam com o Brafitec, no qual os participantes apresentam peso equivalente numa parceria internacional que é sempre complexa. 
Os programas distam em quase duas décadas no que concerne às suas progênies. Assim, apesar de limitações importantes, com destaque para o caráter elitista, o Programa Engenheiro 3i se mostra como mais ajustado ao tempo presente. Mesmo sem escala, coisa que o Brafitec apresenta, o Programa $3 \mathrm{i}$ oferece coisas novas para serem consideradas em políticas públicas. Na direção da internacionalização, apesar de avanços importantes, as principais universidades brasileiras, notadamente as públicas, ainda precisam "internacionalizar-se".

\section{CONSIDERAÇÕES FINAIS}

Os Programas Engenheiro 3i e Brafitec atuam no Brasil e na França com exclusividade para os cursos de engenharia. O Programa Engenheiro $3 i$ nasceu em 2017. Envolvendo duas universidades, ele tem financiamento desbalanceado entre os lados francês e brasileiro. Nele, o aluno é trilíngue, trabalha em equipe com colegas selecionados do país de origem e do estrangeiro e tem uma empresa parceira atuando nos dois países. O Programa Brafitec nasceu em 2002. Nele, várias universidades do Brasil e da França estão envolvidas, os participantes têm financiamento integral, o aluno é bilíngue, o trabalho em equipe entre os membros selecionados não é exigência do Programa e não há a presença de empresa fazendo parte dele.

O Programa Engenheiro 3i, mais atual, tem alguns pontos que se destacam do Programa Brafitec no aspecto de formação: por proporcionar um percurso formativo complementar, almejando um engenheiro que trabalha em equipe, presencialmente e a distância, na solução de um problema real, estipulado por uma empresa presente nos países sedes das universidades envolvidas; por exigir um domínio comunicativo em três idiomas; e por ser um Programa acompanhado pelas universidades envolvidas e pela empresa parceira do Programa, além de certificado pela UTFPR e pela UTC. O Programa Brafitec se destaca do Programa Engenheiro $3 i$ no aspecto financiamento, ofertando apoio financeiro aos alunos, professores e instituições da França e do Brasil.

O Brafitec tem maturidade, várias edições, investimento e é um programa do governo brasileiro. Ele tem um papel relevante na consolidação de novos programas como o Engenheiro 3i, que é jovem, ainda precisa se aperfeiçoar, tem poucos recursos e é um programa interinstitucional, mas que busca a inovação na formação do engenheiro do futuro.

Conclui-se que programas de mobilidade produzem lições importantes para a internacionalização da universidade pública brasileira, para melhorar a qualidade do seu ensino e da sua pesquisa. Os três $i$ do Programa proposto por duas instituições tecnológicas que querem se internacionalizar aparecem como uma referência importante para se pensar o devir da profissão engenheiro num mundo sem fronteiras.

\section{REFERÊNCIAS}

ANDIFES. Fórum Nacional de Pró-Reitores de Assuntos Estudantis. V Pesquisa Nacional de Perfil Socioeconômico e Cultural dos(as) Graduandos(as) das IFES: 2018. Uberlândia: Andifes, 2019. Disponível em:

<https://www.ufes.br/sites/default/files/anexo/relatorio_executivo_v_pesquisa_do_perfil_dos_grad uandos.pdf $>$. Acesso em: 4 jun. 2021.

ANDIFES. Universidades federais patrimônio da sociedade brasileira. Brasília, DF: Andifes, 2017. Disponível em: <https://www.andifes.org.br/wp-content/uploads/2017/11/AndifesVERSAO-DOWNLOAD-REDES-SOCIAIS-E-WHATSAPP.pdf>. Acesso em: 4 jun. 2021.

BARBOSA, Maria L. de O.; NEVES, C. E. B. Internacionalização da educação superior: instituições e diplomacia do conhecimento. Sociologias, Porto Alegre, v. 22, n. 54, p. 22-44, maio/ago. 2020. DOI: $<$ https://doi.org/10.1590/15174522-104425>. Disponível em: <https://www.scielo.br/j/soc/a/gGxRnkpVnt66mMXyTZKW5hn/?lang=pt>. Acesso em: 4 jun. 2021. 
BARDIN, Laurence. Análise de conteúdo. São Paulo: Edições 70, 2016.

BARTELL, Marvin. Internationalization of universities: a university culture-based framework. Higher Education, Winnipeg, v. 45, p. 43-70, 2003. DOI: <https://doi.org/10.1023/A:1021225514599>. Disponível em: < https://link.springer.com/article/10.1023/A:1021225514599>. Acesso em: 4 jun. 2021.

CAPES. Programa BRAFITEC. Edital n 13/2019. Brasília, DF: CAPES, 2019. Disponível em: <https://www.gov.br/capes/pt-br/centrais-de-conteudo/11062019-edital-13-brafitec-pdf>. Acesso em: 5 jun. 2021.

CCS/CAPES. Mobilidade para a França é adiada para setembro de 2021. Disponível em: $<$ https://www.gov.br/capes/pt-br/assuntos/noticias/mobilidade-para-a-franca-e-adiada-parasetembro-de-2021>. Acesso em: 5 jun. 2021.

CECHIN, Marizete R. Estudo comparativo entre a Universidade Tecnológica Federal do Paraná e as universidades de tecnologia da França. Tese (Doutorado em Ensino de Ciência e Tecnologia)

- Universidade Tecnológica Federal do Paraná, Ponta Grossa, 2019. Disponível em:

<http://repositorio.utfpr.edu.br/jspui/handle/1/4041>. Acesso em: 4 jun. 2021.

CECHIN, Marizete R.; PILATTI, Luiz A.; RAMOND, Bruno. Maio de 68: contribuições para nascer a primeira universidade de tecnologia na França. Cadernos de História da Educação, [s.l.], v. 20, e013, 2020. DOI: <https://doi.org/10.14393/che-v20-2021-13>. Disponível em:

<http://www.seer.ufu.br/index.php/che/article/view/58228>. Acesso em: 4 jun. 2021.

CECHIN, Marizete R.; PILATTI, Luiz A.; RAMOND, Bruno. O professor do engenheiro 3i: perfil para a indústria, a inovação e a interculturalidade. Tecné, Episteme y Didaxis: TED, [s.l.], p. 1-6, 2018. Disponível em: <https://revistas.pedagogica.edu.co/index.php/TED/article/view/8688>. Acesso em: 4 jun. 2021.

CHARLE, Christophe. Jalons pour une histoire transnationale des universités. Revue d'Histoire Critique, Paris, v. 121, p. 21-42, 2013. DOI: < https://doi.org/10.4000/chrhc.3147>. Disponível em: $<$ https://journals.openedition.org/chrhc/3147>. Acesso em: 4 jun. 2021.

CZIULIK, Carlos et al. 3i engineer: an approach based on a Brazilian-French collaboration. In: BORSATO, Milton et al. (ed.). Transdisciplinary engineering: crossing boundaries. Curitiba: Amsterdam: IOS Press Ebooks, 2016. p. 368-377. Disponível em:

<https://ebooks.iospress.nl/publication/45417>. Acesso em: 4 jun. 2021.

DIAS, Filipe J.; NUNES, Rogério da S. A internacionalização das universidades federais do sul do Brasil. In: COLÓQUIO INTERNACIONAL DE GESTÃ̃O UNIVERSITÁRIA, 17., Mar del Plata. Anais... Mar del Prata: Universidad Nacional de Mar del Plata; Florianópolis: Universidade Federal de Santa Catarina, 2017. Disponível em:

<https://repositorio.ufsc.br/xmlui/bitstream/handle/123456789/181006/101_00258.pdf?sequence= 1\&isAllowed=y $>$. Acesso em: 4 jun. 2021.

ESCOBAR, Helton. Universidades brasileiras devem promover internacionalização, valorizar mérito, flexibilizar regras e reduzir burocracia se quiserem chegar à elite do ensino superior. Ensino Superior Unicamp, Campinas, 17 out. 2013. Disponível em:

$<$ https://www.revistaensinosuperior.gr.unicamp.br/notas/universidades-brasileiras-devem-promoverinternacionalizacao-valorizar-merito-flexibilizar-regras-e-reduzir-burocracia-se-quiserem-chegar-a-elitedo-ensino-superior>. Acesso em: 4 jun. 2021.

GELAS, Jacques. As lições e as vantagens do Programa Brafitec. Brasília, DF: Fórum Franco- 
Brasileiro da Educação Superior e Pesquisa, 2009. Disponível em:

$<$ http://portal.mec.gov.br/index.php?option $=$ com_docman\&view $=$ download\&alias $=1927$-jacquesgelas-traducao\&category_slug=novembro-2009-pdf\&Itemid=30192>. Acesso em: 4 jun. 2021.

GELAS, Jacques. Programme Brafitec: BRAsil France Ingénieurs TEChonologie. In : FORUM BRAFITEC. 15., 2019, Uberlândia. Anais... Uberlândia: UFU; UFTM; Instituto Federal do Triângulo Mineiro, 2019. Disponivel em: <https://fr.readkong.com/page/brasil-france-ingenieurs-technologie9521090>. Acesso em: 28 jun. 2021.

GROCHOCKI, Luís F. de M. A contribuição da CAPES para a internacionalização das engenharias no Brasil: o caso do Programa Brafitec. Dissertação (Mestrado em Educação em Ciências: Química da Vida e Saúde) - Universidade Federal do Rio Grande do Sul, Porto Alegre, 2016 . Disponível em: <http://hdl.handle.net/10183/148585>. Acesso em: 4 jun. 2021.

GROCHOCKI, Luís F. de M. The contribution of Brafitec to the internationalization of Brazilian engineering undergraduate courses. Montpellier: [s.n.], 2016b. Disponível em: $<$ https://ouebe.polytech.umontpellier.fr/BRAFITEC/images/presentations/2juin/Apresentacao_FO RUM.pdf>. Acesso em: 4 jun. 2021.

LIMA, Manolita C.; MARANHÃO, Carolina M. S. de A. Políticas curriculares da internacionalização do ensino superior: multiculturalismo ou semiformação? Ensaio: Avaliação e Políticas Públicas em Educação, Rio de Janeiro, v. 19, n. 72, p. 575-598, jul./set. 2011. DOI:

<https://doi.org/10.1590/S0104-40362011000400007>. Disponível em: <https://www.scielo.br/j/ensaio/a/hpY6szZwWw6HztCYhLyXVjh/?lang=pt\#. Acesso em: 4 jun. $2021>$.

LEITE, Denise; GENRO, Maria E. H. Avaliação e internacionalização da educação superior: quo vadis Amarica Latina? Avaliação: Revista da Avaliação da Educação Superior (Campinas), Sorocaba, v. 17, n. 3, p. 763-785, nov. 2012. DOI: <https://doi.org/10.1590/S1414-40772012000300009>. Disponível em: <https://www.scielo.br/j/aval/a/ccHKjgXTrG7cp75QVdRC7sz/?lang=pt>. Acesso em: 4 jun. 2021.

LEQUIN, Yves-Claude. Des universités de technologie en villes moyennes: origine, implantation et effets. In: LEVY, R.; SOLDANO, C.; CUNTIGH, P. (ed.). L'université et ses territoires. Grenoble: Presses Universitaires de Grenoble, 2015. p. 77-95. Disponível em: < https://www.cairn.info/luniversite-et-ses-territoires--9782706122323-page-77.htm>. Acesso em: 4 jun. 2021.

MARGINSON, Simon; RHOADES, Gary. Beyond national states, markets, and systems ofhigher education: A glonacal agency heuristic. Higher Education, v.43, p. 281-309, 2002. Disponível em: <https://link.springer.com/article/10.1023\%2FA\%3A1014699605875>. Acesso em: 2 maio 2021.

MOROSIN, Marília C. Estado do conhecimento sobre internacionalização da educação superior: conceitos e práticas. Educar em Revista, Curitiba, n. 28, p. 107-124, 2006. DOI: $<$ https://doi.org/10.1590/S0104-40602006000200008>. Disponível em: <https://www.scielo.br/j/er/a/k4qqgRK75hvVtq4Kn6QLSJy/abstract/?lang=pt\#>. Acesso em: 4 jun. 2021.

NÓBREGA, Maria H. da. Intercâmbios educacionais e diversidade cultural: implicações para o ensino de português para falantes de outras línguas. Revista Brasileira de Linguística Aplicada, [s.l.], v. 14, n. 1, p. 61-81, mar. 2014. DOI: <https://doi.org/10.1590/S1984-63982014005000003 > Disponível em: <https://www.scielo.br/j/rbla/a/nnyStBxhsDWkfQKKhNdvVPw/?lang=pt>. Acesso em: 4 jun. 2021.

OREGIONI, María. S. La internacionalización universitaria desde una perspectiva situada: tensiones y 
desafíos para la región Latinoamericana. Revista Internacional de Educação Superior, [s.l.], v. 3, n. 1, p. 114-133, 2017. DOI: <https://doi.org/10.22348/riesup.v3i1.7667>. Disponível em:

$<$ https://periodicos.sbu.unicamp.br/ojs/index.php/riesup/article/view/8650578>. Acesso em: 4 jun. 2021.

RAMOND, Bruno. INGÉNIEUR-3i. Compiègne: University of Technology of Compiègne, 2017. 30 slides, color. Material Particular.

SANTOS, Boaventura de S. El rol de la universidad en la construcción de una globalización alternativa. In: Global University Network for Innovation (org.). La educación superior en el mundo 2008:

nuevos retos y roles emergentes para el desarrollo humano y social. Madrid: Mundiprensa, 2008. p. 169171. Disponível em: <https://upcommons.upc.edu/handle/2099/7981>. Acesso em: 4 jun. 2021.

SOUZA, Cláudio J. et al. Maturidade acadêmica: uma questão de mudança de paradigma. Research, Society and Development, [s.l.], v. 9, n. 6, e40963437, 2020. DOI: <http://dx.doi.org/10.33448/rsdv9i6.3437>. Disponível em: < https://rsdjournal.org/index.php/rsd/article/view/3437/3715>. Acesso em: 4 jun. 2021.

STALLIVIERI, Luciane. Comprendendo a internationalização da educação superior. Revista de Educação do Cogeime, [s.l.], ano 26, n. 50, p. 15-36, jan./jun. 2017. Disponível em:

<https://www.metodista.br/revistas/revistas-cogeime/index.php/COGEIME/article/view/729>. Acesso em: 6 jun. 2021.

UNESCO. Política de mudança e desenvolvimento no ensino superior. Rio de Janeiro: Garamond, 1999. Disponível em: <https://unesdoc.unesco.org/ark:/48223/pf0000129768>. Acesso em: 4 jun. 2021.

UTC. L’UTC: 40 ans d'histoire de'innovation. Compiègne: [s.n.], 2013.

UTC. Guide de l'étudiant 2020/2021. Compiègne, France: UTC/Sorbonnne Universites, 2020. Disponível em: <https://www.utc.fr/wp-content/uploads/sites/28/2020/04/Guideetu2020-21web.pdf >. Acesso em: 19 jun. 2021.

UTFPR. Chamada de seleção para Programa Brafitec/CAPES ano 2018. Edital nº 08/2018PROGRAD. Curitiba: UTFPR. 2018. Disponível em: < http://portal.utfpr.edu.br/editais/graduacao-eeducacao-profissional/reitoria/internacionalizacao/2018/chamada-de-selecao-para-o-programabrafitec-capes-2018/@@display-file/arquivo_edital/Edital\%20Brafitec\%202018.pdf>. Acesso em: 19 jun. 2021.

UTFPR. Programa de dupla diplomação em engenharia - UTFPR e universidades francesas. Edital n 25/2021-PROGRAD. Curitiba: UTFPR. 2021. Disponível em:

$<$ https://sei.utfpr.edu.br/sei/publicacoes/controlador_publicacoes.php?acao=publicacao_visualizar\&i d_documento=2116833\&id_orgao_publicacao=0>. Acesso em: 19 jun. 2021.

UTFPR. Chamada de seleção para o Programa Engenheiro 3i: Período 2018/2020. Curitiba: UTFPR, 2017. Disponível em:

<http://www.utfpr.edu.br/internacional/chamadas/2017/edital_engenheiro-3i.pdf>. Acesso em: 4 jun. 2021.

WIT, Hans. de. Repensando o conceito de internacionalização. Ensino Superior Unicamp, Campinas, 20 fev. 2013. Disponível em: <https://www.revistaensinosuperior.gr.unicamp.br/international-highereducation/repensando-o-conceito-da-internacionalizacao >. Acesso em: 4 jun. 2021.

WUNENBURGER, Jean-Jacques. Les relations internationales dans les universités. In: BATS, R. (dir.). 
Mener un projet international: bibliothèques françaises et coopération internationale. Villeurbanne: Presses de l'enssib, 2017. p. 124-129. Disponível em:

<https://books.openedition.org/pressesenssib/487>. Acesso em: 4 jun. 2021.

Submetido: $01 / 12 / 2020$ Aprovado: 07/07/2021 